\title{
Degree of conversion of nanofilled and microhybrid composite resins photo-activated by different generations of LEDs
}

Benicia Carolina laskieviscz RIBEIRO'1, Juliana Maria Capelozza BOAVENTURA², Joel de BRITO-GONÇALVES ${ }^{3}$, Alessandra Nara de Souza RASTELLI" ${ }^{4}$, Vanderlei Salvador BAGNATO 5 , José Roberto Cury SAAD ${ }^{4}$

\footnotetext{
1- DDS, MSc, PhD Professor, Dental School Prof. Albino Coimbra Filho, Federal University of Mato Grosso do Sul, Campo Grande, MS, Brazil.

2- DDS, MSc, PhD student, Department of Restorative Dentistry, Araraquara School of Dentistry, UNESP - Univ. Estadual Paulista , Araraquara, SP, Brazil.

3- DDS, Dental School Prof. Albino Coimbra Filho, Federal University of Mato Grosso do Sul, Campo Grande, MS, Brazil.

4- DDS, MSc, PhD, Assistant Professor, Department of Restorative Dentistry, Araraquara School of Dentistry, UNESP - Univ. Estadual Paulista , Araraquara, SP, Brazil.

5- DDS, MSc, PhD, Full Professor, Biophotonics Laboratory, Physics Institute of São Carlos, University of São Paulo, São Carlos, SP, Brazil.
}

Corresponding address: Benicia Carolina laskieviscz Ribeiro - Rua Goiás, 449 - Jardim dos Estados - Campo Grande - MS - Brazil - 79.020 -100 - Phone:+55 67 3326-1480 - e-mail: becarol.odonto@uol.com.br

Received: June 16, 2010 - Modification: May 31, 2011 - Accepted: July 14, 2011

\section{ABSTRACT}

$\mathrm{O}$ bjective: This study aimed at evaluating the degree of conversion (DC) of four composite resins, being one nanofilled and 3 microhybrid resins, photo-activated with secondand third-generation light-emitting diodes (LEDs). Material and methods: Filtek ${ }^{\top M}$ Z350 nanofilled composite resins and Amelogen ${ }^{\circledR}$ Plus, Vit-I-escence ${ }^{\mathrm{TM}}$ and Opallis microhybrid resins were photo-activated with two second-generation LEDs (Radii-cal and Elipar Free Light $^{T M}$ 2) and one third-generation LED (Ultra-Lume LED 5) by continuous light mode, and a quartz halogen-tungsten bulb (QHT, control). After $24 \mathrm{~h}$ of storage, the samples were pulverized into fine powder and $5 \mathrm{mg}$ of each material were mixed with $100 \mathrm{mg}$ of potassium bromide $(\mathrm{KBr})$. After homogenization, they were pressed, which resulted in a pellet that was evaluated using an infrared spectromer (Nexus 470, Thermo Nicolet) equipped with TGS detector using diffuse reflectance ( 32 scans, resolution of $4 \mathrm{~cm}^{-1}$ ) coupled to a computer. The percentage of unreacted carbon-carbon double bonds $(\% \mathrm{C}=\mathrm{C})$ was determined from the ratio of absorbance intensities of aliphatic $C=C$ (peak at $1637 \mathrm{~cm}-1$ ) against internal standard before and after curing of the specimen: aromatic $\mathrm{C}-\mathrm{C}$ (peak at $1610 \mathrm{~cm}-1$ ). Results: The ANOVA showed a significant effect on the interaction between the light-curing units (LCUs) and the composite resins $(p<0.001)$. The Tukey's test showed that the nanofilled resin (Filtek ${ }^{\mathrm{TM}} \mathrm{Z350}$ ) and Opallis when photo-activated by the halogen lamp (QTH) had the lowest DC compared with the other microhybrid composite resins. The DC of the nanofilled resin (Filtek ${ }^{\mathrm{TM}}$ Z350) was also lower using LEDs. The highest degrees of conversion were obtained using the third-generation LED and one of second-generation LEDs (Elipar Free Light ${ }^{\mathrm{TM}}$ 2). Conclusions: The nanofilled resin showed the lowest DC, and the Vit-I-escence ${ }^{T M}$ microhybrid composite resin showed the highest DC. Among the LCUs, it was not possible to establish an order, even though the second-generation LED Radii-cal provided the lowest DC.

Key words: Composite resins. Fourier transform infrared spectroscopy. Nanotechnology. Light. 


\section{INTRODUCTION}

Although widely used in diverse industries such as biomedicine, electronics, aerospace, and means of transportation, it is only recently that nanotechnology has begun to be applied to Dentistry ${ }^{8}$. Due to their small size, it is possible to incorporate more filler content on composite resins based on this technology ${ }^{10}$, which results in better mechanical properties ${ }^{8}$. Their optical properties are also improved, since the diameter of its particles is a fraction of a visible light wavelength, and the human eye cannot distinguish them ${ }^{8}$.

Given its many deficiencies, such as short life and heat production ${ }^{5}$, quartz-tungsten halogen (QTH) lamps are being replaced by other light sources, especially light-emitting diodes (LEDs). Technical advancements in LED light-curing units (LCUs) have occurred rapidly since their introduction to Dentistry, and second-generation blue LED systems are capable of performing equal to QTH LCUs ${ }^{17}$. The first-generation units consisted of an array of relatively low-powered chips offering a comparative low output and poor curing performance compared with QTH LCUs ${ }^{15}$. Second-generation models demonstrate better performance, using a single chip of much higher surface area that emits only one color range of grealy incresead output power ${ }^{26}$. Currently, the LEDs systems are already in their third generation, characterized by the presence of the same chip used by the second-generation systems plus other low-powered chips which will emit a second frequency in the violet spectral range ${ }^{17}$.

Composite resins with polymer matrices that exhibit bifunctional monomers (Bis-GMA, BisEMA, TEGDMA) whose polymerization reaction generates glassy polymers with dense crosslinked networks ${ }^{23}$. Ideally, composites should have most of their monomers converted into polymers during polymerization. Resin-based material polymerization involves free radical reaction in which the material is transformed from a viscous to a rigid state. During this process, the terminal aliphatic $\mathrm{C}=\mathrm{C}$ bonds are broken and converted to primary $\mathrm{C}-\mathrm{C}$ covalent bonds between methacrylate monomers. As polymerization progresses, however, the diffusion rate of the propagating free radicals undergoes a strong reduction. Thus, monomer conversion is not complete and, at the end of the reaction, part of the monomers remains as pendant double bonds or unreacted monomers trapped in the polymeric matrix ${ }^{12}$. Nevertheless, the dimethacrylate polymers exhibit considerable residual unsaturation in the final product, with a degree of conversion (DC) ranging from 55 to $75 \% 6,19$. The literature shows that the formation mechanism of free radical in the polymer varies with the photoinitiator system used ${ }^{25}$. Authors like Conti, et al. $^{2}$ (2005) consider that the emission spectra of LCUs and absorption photoinitiators are essential for adequate polymerization.

The physical and mechanical properties of photocured composites are directly influenced by the level of conversion achieved during polymerization ${ }^{9}$. Lower degree of conversion provides composites with inferior mechanical properties and greater discoloration and degradation ${ }^{20}$ and as a result, restorations with poor wear resistance and poor color permanence ${ }^{18}$.

The purpose of this study was to investigate the influence of different light sources - three LEDs, two of the second and one of the third generations on the DC of nanofilled and microhybrid composite resins.

\section{MATERIAL AND METHODS}

\section{Composite resins}

A nanofilled composite resin (Filtek ${ }^{\text {TM }} \mathrm{Z350}$ ) and three microhybrid composite resins (Amelogen ${ }^{\circledR}$ Plus, Vit-I-escence ${ }^{T M}$ and Opallis), all indicated for dentin at shade $A_{2}$, were used. The characteristics and manufacturers of the composite resins can be seen in Figure 1.

\section{Light-curing units}

Two second-generation LEDs - Radii-cal (SDI Dental Product SDI, Bayswater, Vitoria, Australia) and Elipar Free Light ${ }^{\mathrm{TM}} 2$ (3M ESPE Dental Products, St. Paul, MN, USA) - and one third-generation LED - Ultra-Lume LED 5 (Ultradent, South Jordan UTAH, USA) - were used. A halogen LCU (Ultralux; Dabi Atlante, Ribeirão Preto, SP, Brazil) was used as the control group. The power was measured before specimen preparation at the end of the light-guide tip of all LCUs with a power meter (Fieldmaster, Coherent Commercial Products Division, Santa Clara, CA, USA, model FM, series 11M96) and the power density values were calculated using the equation: $I=P / A$, where $\mathrm{P}$ is the power, in milliwatts, and $\mathrm{A}$ is the light tip area, in square centimeters.

Figure 2 shows the the main characteristics of the LCUs used in this study.

\section{Specimen preparation}

To obtain the samples, a circular matrix of aluminum with an external diameter of $2.5 \mathrm{~cm}$ and a central diameter of $4 \mathrm{~mm}$, and depth of 2 $\mathrm{mm}$ was used. A mylar strip was placed on a glass plate, and the matrix was positioned over that. Using a CIGFTMIN 3 spatula (Oraltech, São Paulo, $\mathrm{SP}$, Brazil), the composite resin was placed in the central orifice in a single increment. A second mylar strip was placed over the composite resin and another glass plate was slightly compressed in order 


\begin{tabular}{|c|c|c|c|c|c|}
\hline & $\begin{array}{l}\text { Polymer } \\
\text { matrix }\end{array}$ & Filler content & $\%$ Load & $\begin{array}{c}\text { Batch } \\
\text { number }\end{array}$ & Manufacturer \\
\hline $\begin{array}{c}\text { Vit-I. } \\
\text { escence }^{T M}\end{array}$ & $\begin{array}{l}\text { Bis-GMA } \\
\text { TEGDMA }\end{array}$ & $\begin{array}{c}\text { Strontium Glass } \\
\text { Boron Aluminum Silicate with } \\
\text { silica particles from } 0.4-0.7 \mu \mathrm{m}\end{array}$ & $\begin{array}{l}58 \% \text { vol. } \\
75 \% \text { weight }\end{array}$ & B2W76 & $\begin{array}{c}\text { Ultradent, South Jordan, } \\
\text { UT, USA }\end{array}$ \\
\hline $\begin{array}{l}\text { Amelogen } \AA \\
\text { Plus }\end{array}$ & $\begin{array}{l}\text { Bis-GMA } \\
\text { TEGDMA }\end{array}$ & $\begin{array}{l}\text { Barium Boron Aluminum } \\
\text { particles from 0.4-0.7 } \mu \mathrm{m}\end{array}$ & $\begin{array}{c}61 \% \text { vol. } \\
78 \% \text { weight }\end{array}$ & B2XGJ & $\begin{array}{c}\text { Ultradent, South Jordan, } \\
\text { UT, USA }\end{array}$ \\
\hline Opallis & $\begin{array}{l}\text { Bis-GMA } \\
\text { Bis-EMA } \\
\text { TEGDMA }\end{array}$ & $\begin{array}{l}\text { Barium-Aluminum Glass } \\
\text { Silanized silica } \\
\text { Pigments and silicas particles } \\
\text { from } 40 \mathrm{~nm} \text { to } 3.0 \mu \mathrm{m}\end{array}$ & $\begin{array}{l}57.8 \% \text { vol. } \\
78.5 \% \text { to } \\
79 \% \text { weight }\end{array}$ & 090109 & $\begin{array}{l}\text { FGM Dental Products, } \\
\text { Joinville, SC, Brazil }\end{array}$ \\
\hline Filtek $^{\text {TM }} \mathrm{Z} 350$ & $\begin{array}{l}\text { Bis-GMA } \\
\text { Bis-EMA } \\
\text { TEGDMA }\end{array}$ & $\begin{array}{l}\text { Primary silica (non-agglomerated) } \\
\text { Average size of } 20 \mathrm{~nm} \text { and } \\
\text { zirconium and } \\
\text { silica agglomerates with particles } \\
\text { between } 5 \text { and } 20 \mathrm{~nm} \text { forming } \\
\text { agglomerates of } 0.6 \text { to } 1.4 \mu \mathrm{m}\end{array}$ & $\begin{array}{c}84.5 \% \text { vol. } \\
78.5 \% \text { weight }\end{array}$ & $6 \mathrm{CY}$ & $\begin{array}{c}\text { 3M ESPE Dental Products, } \\
\text { St. Paul, MN, USA }\end{array}$ \\
\hline
\end{tabular}

Figure 1- Main characteristics of the composite resins used in the study

\begin{tabular}{|c|c|c|c|c|c|}
\hline Unit & $\begin{array}{c}\text { Number } \\
\text { of LEDs }\end{array}$ & $\begin{array}{c}\text { Wavelength } \\
\text { range }\end{array}$ & Power density & Diameter & $\begin{array}{c}\text { Serial } \\
\text { number }\end{array}$ \\
\hline Ultra Lume LED 5 & 5 & $370 \mathrm{~nm}-500 \mathrm{~nm}$ & $800 \mathrm{~mW} / \mathrm{cm}^{2}$ & $\begin{array}{c}10 \mathrm{~mm} \times 13 \mathrm{~mm}, \\
\text { oval }\end{array}$ & 509510 \\
\hline Radii-cal & 1 & $440 \mathrm{~nm}-480 \mathrm{~nm}$ & $970 \mathrm{~mW} / \mathrm{cm}^{2}$ & $7 \mathrm{~mm}$, circular & 415614 \\
\hline Elipar FreeLight ${ }^{\text {TM } 2}$ & 1 & $430 \mathrm{~nm}-480 \mathrm{~nm}$ & $980 \mathrm{~mW} / \mathrm{cm}^{2}$ & $8 \mathrm{~mm}$, circular & 939826018134 \\
\hline Ultralux (QTH) & - & $400 \mathrm{~nm}-500 \mathrm{~nm}$ & $426 \mathrm{~mW} / \mathrm{cm}^{2}$ & $8 \mathrm{~mm}$, circular & 4366 \\
\hline
\end{tabular}

Figure 2- Characteristics of light-curing units used in this study

to regularize the external surface of the samples.

The light-guide tips of the LCUs were placed over the matrix containing the composite resin at a standardized distance of $2 \mathrm{~mm}$ from the top surface of the material and photo-activation was done during $40 \mathrm{~s}^{16}$. After photo-activation, the specimens were stored under dry conditions at room temperature in light-proof containers ${ }^{4}$, and identified according to the study groups.

After $24 \mathrm{~h}$, the composite resin was pulverized into fine powder. The pulverized composite resin was maintained in a dark room until the moment of the Fourier transform-infrared spectroscopy (FTIR) analyses. Five milligrams of the ground powder were thoroughly mixed with $100 \mathrm{mg}$ of $\mathrm{KBr}$ powder salt. This mixture was placed into a pelleting device and then pressed in a press with a load of 10 tons during 1 min to obtain a pellet ${ }^{17}$.

\section{Determination of the DC (\% DC)}

The number of double-carbon bonds that are converted into single bonds provides the DC (\% DC) of the composite resin. To measure the DC, the pellet was placed into a holder attachment into the spectrometer (Nexus 470 Thermo Nicolet, Vernon
Hills, IL, USA). For this technique, the samples were made and analyzed $24 \mathrm{~h}$ after the photoactivation. The FT-IR spectra of both uncured and cured samples were analyzed using an accessory of the diffuse reflectance. The measurements were recorded in the absorbance operating under the following conditions: 32 scans, a $4 \mathrm{~cm}^{-1}$ resolution, and a 300 to $4000 \mathrm{~cm}^{-1}$ wavelength. The percentage of unreactive carbon-carbon double bonds ( $\% \mathrm{C}=\mathrm{C}$ ) was determined from the ratio of the absorbance intensities of aliphatic $\mathrm{C}=\mathrm{C}$ (peak at $1638 \mathrm{~cm}^{-1}$ ) against an internal standard before and after the curing of the specimen: aromatic C-C (peak at $1608 \mathrm{~cm}^{-1}$ ). The DC was determined by subtracting the $\% \mathrm{C}=\mathrm{C}$ from $100 \%$, according to the equation: $D C \%$ conversion $=\left\{1-\frac{\left(1638 \mathbf{m}^{-1} / 1608 \mathbf{m}^{-1}\right) \text { cured }}{\left(1638 \mathbf{m}^{-1} / 1608 \mathbf{m}^{-1}\right) \text { uncured }}\right\} \times 100 \%$

The assessment of the DC was carried out by two-way analysis of variance (ANOVA). Multiple comparisons of DC means by the Tukey's test followed the analysis. All statistical analyses were performed at a $5 \%$ significance level. 
Table 1- Averages and standard deviations ( $(\mathrm{SD})$ for the degree of conversion

\begin{tabular}{|c|c|c|c|c|}
\hline Light-Curing Unit (LCUs) & Composite Resin & Mean (\%) & $( \pm S D) S D$ & \\
\hline \multirow[t]{4}{*}{ Ultralux } & Filtek $^{\text {TM }}$ Z350 & 55.36 & 0.72 & c \\
\hline & Opallis & 56.12 & 1.26 & c \\
\hline & Amelogen ${ }^{\circledR}$ Plus & 60.53 & 1.37 & ef \\
\hline & Vit-I-escense $^{\mathrm{TM}}$ & 67.82 & 0.60 & $\mathrm{ij}$ \\
\hline \multirow[t]{4}{*}{ Ultra Lume LED 5} & Filtek $^{\text {TM }} Z 350$ & 54.71 & 0.36 & $b c$ \\
\hline & Opallis & 60.52 & 0.39 & ef \\
\hline & Amelogen ${ }^{\circledast}$ Plus & 62.61 & 0.53 & $\mathrm{fg}$ \\
\hline & $V_{\text {Vit-I-escense }}{ }^{\mathrm{TM}}$ & 66.26 & 1.71 & hi \\
\hline \multirow[t]{4}{*}{ Raddi-cal } & Filtek ${ }^{\top \mathrm{TM}} \mathrm{Z} 350$ & 49.77 & 1.10 & a \\
\hline & Opallis & 55.56 & 0.66 & c \\
\hline & Amelogen ${ }^{\circledR}$ Plus & 56.52 & 0.70 & $c d$ \\
\hline & Vit-I-escenseTM & 64.41 & 2.62 & gh \\
\hline \multirow[t]{4}{*}{ Elipar Free Light ${ }^{\mathrm{TM}} 2$} & Filtek $^{\mathrm{TM}} \mathrm{Z350}$ & 52.50 & 0.70 & $\mathrm{~b}$ \\
\hline & Opallis & 58.77 & 0.29 & de \\
\hline & Amelogen ${ }^{\circledast}$ Plus & 60.43 & 1.12 & ef \\
\hline & Vit-I-escense ${ }^{T M}$ & 69.70 & 1.80 & j \\
\hline
\end{tabular}

Means followed by the same letters are not significantly different (Tukey test, $p>0.05$ )

\section{RESULTS}

There was a significant effect on the interaction between the light-curing units (LCUs) and the composite resins $(p<0.001)$. As can be seen in Table 1, the nanofilled Filtek ${ }^{\text {TM }}$ Z350 composite resin showed the lowest DC for all light-curing units used. The lowest DC was obtained with the use of second-generation LED Raddi-cal (49.77\%), while the best performance was achieved with the use of the QTH (55.36\%), but without a statistically significant difference when compared with the thirdgeneration LED Ultra-Lume LED 5 (54.71\%). The microhybrid resins Opallis and Amelogen ${ }^{\circledR}$ Plus had intermediate values for all LCUs used. The highest percentage of conversion of monomers into polymer composite was obtained with Vit-I-escence ${ }^{\mathrm{TM}}$ microhybrid resin photoactivated with any of the LCUs. However no statistically significant difference was observed for Elipar Free Light ${ }^{\mathrm{TM}} 2$ (69.70\%) and Ultralux (67.82\%). Comparisons among the DC mean values according to the LCUs were as follows: Ultralux (Filtek ${ }^{\mathrm{TM}} \mathrm{Z350}=$ Opallis $^{\circledR}<$ Amelogen Plus $^{\circledR}<$ Vit-I-escence ${ }^{T M}$ ), Ultra-Lume LED 5 (Filtek ${ }^{\mathrm{TM}}$ Z350< Opallis ${ }^{\circledR}=$ Amelogen Plus ${ }^{\circledR}<$ Vit-l-escense $\left.{ }^{\mathrm{TM}}\right)$, Radii-Cal (Filtek ${ }^{T M}$ Z350<Opallis ${ }^{\circledR}=$ Amelogen Plus $^{\circledR}<$ Vit-l-escence $\left.{ }^{\top M}\right)$ and Elipar Free Light ${ }^{T M} 2$ (Filtek $^{\text {TM }}$ Z350< Opallis $^{\circledR}=$ Amelogen Plus $^{\circledR}<$ Vit-Iescence $\left.^{T M}\right)$.

It is possible to state that, independent of the LCU, the composite resins can be arranged in a crescent order according to their DC mean values: Filtek $^{\mathrm{TM}} \mathrm{Z} 350 \leq$ Opallis $\leq$ Amelogen ${ }^{\circledR}$ Plus $<$ Vit-I- escence $^{\mathrm{TM}}$. Among the LCUs it was not possible to establish any order according to the DC mean values.

\section{DISCUSSION}

The size of the charged particle and the refractive index, the densities of restorative materials, the nature of polymer matrix and the irradiance time generated by the method of polymerization can influence the DC of dental composite. There is consensus in the literature 20,21 that when inadequate levels of conversion are achieved in the polymerization reaction, the mechanical properties and abrasion resistance performance can be compromised, and color stability may decline ${ }^{20}$.

It is known that physical properties of light-cured composites may change according to the distance from the irradiated surface and, to minimize the chances of interference in this study, the space between the light guide tip and the samples was set at $2 \mathrm{~mm}^{24}$. This distance was chosen because the authors ${ }^{5}$ consider it the shortest distance between the LCU light-guide tip and the bottom of a Class I composite restoration. FT-IR was chosen to analyze the DC because it is an efficient and frequently used technique ${ }^{13,21}$ and provides a better understanding of these materials, which is expected to optimize the polymerization process ${ }^{9}$. Infrared or heat radiation is an electromagnetic radiation invisible to the human eye which limits the length of the visible spectrum from $750 \mu \mathrm{m}$ to $0.5 \mathrm{~mm}$ and triggers both the vibration and rotation of 
molecules. This spectroscopy is based on the fact that molecules absorb electromagnetic radiation in the IR region. These reactive molecules are related to the presence of individual functional groups that give rise to absorption bands in certain defined areas of the spectrum ${ }^{27}$.

In a recent study ${ }^{14}$, results for DC, when one composite resin was light-cured with LED were significantly higher than those obtained with halogen light curing, which can be explained by their wavelengths ${ }^{24}$. However, the difference in our study was caused not only by the wavelength, but probably also by the different irradiance emitted by LCUs or even the organic components of the composite resins. Unlike Polydorou, et al. ${ }^{14}$ (2008) study, we found that the halogen light (QTH) provided the best results for the nanofilled resin. Probably, the heat generated by the QTH lamp has influenced the conversion of monomers into polymers. The gradual increase in temperature influences the polymerization reaction ${ }^{3}$ although the heat produced by halogen LCUs may cause deleterious effects to the pulp ${ }^{16}$. However, other studies are necessary to elucidate this fact because this result did not happen with the other composites. It is likely that the exposure time and power density and consequently energy density can be related with the results obtained in this study ${ }^{6,10}$.

Nonetheless, when the nanofilled and microhybrid composites were compared, the DC of the first one was lower than that of the other resins lightcured by all LCUs used in this study. These results are in accordance with those obtained by Silva, et al. ${ }^{22}$ (2008) and Halvorson, et al. ${ }^{5}$ (2002) in which the nanofilled resin showed a lower DC. A possible explanation for this performance may be related to the difference in the composition of the organic matrix, size, volume and type of particles that interfere with the depth of cure and different spread pattern of incident light ${ }^{7}$. The particles can cause an effect of dispersing the light because as light passes through the increasing density of the material, its light intensity is reduced ${ }^{28}$. It is greatly outstanding that the results with the nanofilled resin showed the lowest DC among all composites that were analyzed in this study, which is similar to the results obtained by Silva, et al.22 (2008). Those authors ${ }^{22}$ showed that non-agglomerated silica nanoparticles with mean size of $20 \mathrm{~nm}$ may have caused a light-scattering effect in nanofilled composite. Thus, the power density might have been attenuated and the DC decreased. On the other hand, in the microhybrid composite, light transmittance was probably higher, which can explain the results obtained in this investigation.

When Opallis composite resin was light-cured with Elipar Free Light ${ }^{\mathrm{TM}} 2$ and Ultra Lume LED 5 it was observed the highest DC mean values.
Amelogen ${ }^{\circledR}$ Plus showed no statistically significant differences when light-cured by three of the four LCUs (Ultralux QTH, LEDs Ultra Lume LED 5 and Elipar Free Light ${ }^{T M} 2$ ). Its lower performance occurred when LED Raddi-cal was used.

The highest conversion of monomers into polymers was observed for Vit-I-escence ${ }^{\mathrm{TM}}$ composite resin irrespective of the LCU, with a slight increase when Elipar Free Light ${ }^{\mathrm{TM}} 2$ was used. However, all composite resins showed a lower DC when lightcured with Radii-Cal. In spite of these results, it is known that blue LEDs have the advantage of a narrower spectral range than QTH lamps and a better connection between the emitted light and the absorption and photoinitiator camphorquinone ${ }^{11}$. In this particular case, there was a slight decline in LED ability to convert monomers into polymers, when compared with the other LCUs used in this study.

According to $\mathrm{Nitta}^{10}$ (2005), the light-guide tip diameter can influence the DC. This author ${ }^{10}$ found that the irradiation emitted by a 4-mm-diameter tip was approximately twice that of a 8 -mm-diameter tip and three times that of a $10-\mathrm{mm}$-diameter tip because the light beam may be scattered depending on the type of guide and optical fiber. However, in this study, different sizes of light-guide tips (7, 8 and $13 \mathrm{~mm}$ ) were used and the lowest DC value was obtained with the LED Raddi-cal, which has the smallest tip diameter and has a narrower range of light spectrum (440-480 nm), allowing a better use of the light emitted ${ }^{1}$. This LED provides an intensity of $970 \mathrm{~mW} / \mathrm{cm}^{2}$, which is higher than the one from third-generation LED $\left(800 \mathrm{~mW} / \mathrm{cm}^{2}\right)$, and slightly lower than the one from the other secondgeneration LED (Elipar Free Light ${ }^{T M}$ 2), with 980 $\mathrm{mW} / \mathrm{cm}^{2}$.

In this study, the irradiation time was constant for all LCUs (40 s) but, as shown in Figure 2, the wavelength range, power density, tip diameter were different for the different LCUs. According to Nitta ${ }^{10}$ (2005) the light-guide tip diameter influenced the power density values and the DC mean values. In this study, it was observed that the different dimensions of the light-guide tips did not show statistically significant differences, although the LED with the smallest light-guide tip showed the least performance.

Considering the results obtained in this study, further research is needed in order to elucidate the behavior of nanofilled composites when light-cured with different LCUs.

\section{CONCLUSION}

Based on the results obtained in this study, among the LCUs used, it was not possible to establish an order, even though the secondgeneration LED Raddi-cal showed the lowest DC 
mean values, regardless of the composite resin used. The LCUs did not influence on the final DC of the different composite resins. The microhybrid resin photoactivated with Elipar Free Light $^{\mathrm{TM}} 2$ second-generation LED presented the lowest DC mean values. Among the composite resins, Filtek ${ }^{\mathrm{TM}}$ Z350 showed the lowest DC and Vit-I-escence ${ }^{T M}$ microhybrid composite resin showed the highest DC.

\section{ACKNOWLEDGEMENTS}

In memoriam: Profs. Drs. Maria Salete Machado Candido, UNESP - Univ. Estadual Paulista, Araraquara School of Dentistry, Araraquara, SP, Brazil.

Denis Pablo Jacomassi, Ph.D student in Physics and Materials Science, University of São Paulo, Physics Institute of São Carlos, Optical Group, Biophotonics Laboratory, São Carlos, SP, Brazil for his unconditional support to this study.

3M ESPE Brazil, Dabi-Atlante representative Odontopan and Dr. Patricia Amaral for supplying equipment.

\section{REFERENCES}

1- Asmussen E, Peutzfeldt A. Influence of composition on rate of polymerization contraction of light-curing resin composites. Acta Odontol Scand. 2002;60:146-50.

2- Conti C, Giorginni E, Landi L, Putignano A, Tosi G. Spectroscopic and mechanical properties of dental resin composites cured with different light sources. J Mol Struct. 2005;744-747(Spec. Iss. ):641-6

3- Cunha LG, Alonso RC, Neves AC, Goes MF, Ferracane JL, Sinhoreti MA. Degree of conversion and contraction stress development of a resin composite irradiated using halogen and LED at two C-factor levels. Oper Dent. 2009;34:24-31.

4- Felix CA, Price RB. The effect of distance from light source on light intensity from curing lights. J Adhes Dent. 2003;5:283-91. 5- Halvorson RH, Erickson RL, Davidson CL. Energy dependent polymerization of resin-based composite. Dent Mater. 2002;18:4639.

6- Imazato S, McCabe JF, Tarumi H, Ehara A, Ebisu A. Degree of conversion of composites measured by DTA and FTIR. Dent Mater. 2001; 17:178-83

7- Knezević A, Tarle Z, Meniga A, Sutalo J, Pichler G, Ristić M. Degree of conversion and temperature rise during polymerization of composite resin samples with blue diodes. J Oral Rehabil. 2001:28:586-91.

8- Mitra SB, Wu D, Holmes BN. An application of nanotechnology in advanced dental materials. J Am Dent Assoc. 2003;134:1382-90. 9- Moraes LGP, Rocha RSF, Menegazzo LM, Araújo EB Yukimitu K, Moraes JCS. Infrared spectroscopy: a tool for determination of the degree of conversion in dental composites. J Appl Oral Sci. 2008;16:145-9.
10- Nitta K. Effect of light guide tip diameter of LED-light curing unit on polymerization of light-cured composites. Dent Mater. 2005;21:217-23.

11- Nomura Y, Teshima W, Tanaka N, Yoshida Y, Nahara Y, Okazaki $M$. Thermal analysis of dental resins cured with blue light-emitting diodes (LEDs). J Biomed Mater Res A. 2002;63:209-13.

12- Noronha Filho JD, Brandão NL, Poskus LT, Guimarães JGA, Silva EM. A critical analysis of the degree of conversion of resin-based luting cements. J Appl Oral Sci. 2010;18(5):442-6.

13- Peutzfeldt A, Asmussen E. Resin composite properties and energy density of light cure. J Dent Res. 2005;84:659-62.

14- Polydorou O, Manolakis A, Hellwig E, Hahn P. Evaluation of the curing depth of two translucent composite materials using a halogen and two LED curing units. Clin Oral Investig. 2008;12:4551.

15- Price RB, Felix CA, Andreou P. Evaluation of a dual peak third generation LED curing light. Compend Contin Educ Dent. 2005;26:331-47.

16- Rastelli ANS, Jacomassi DP, Bagnato VS. Changes in the temperature of a dental light-cured composite resin by different light-curing units. Laser Phys. 2008;18:1003-7.

17- Rueggeberg FA, Blalock JS, Callan RS. LED curing lights what's new? Compend Contin Educ Dent. 2005;26:586,588,590-1. 18- Rueggeberg FA, Caughman WF, Curtis JW Jr. Effect of light intensity and exposure duration on cure of resin composite. Oper Dent.1994;19:26-32.

19- Ruyter IE, Oysaed $\mathrm{H}$. Composites for use in posterior teeth: composition and conversion. J Biomed Mater Res A. 1987;21:1123.

20- Schneider LF, Pfeifer CS, Consani S, Prahl SA, Ferracane JL. Influence of photoinitiator type on the rate of polymerization, degree of conversion, hardness and yellowing of dental resin composites. Dent Mater. 2008;24:1169-77.

21- Sideridou I, Tserki V, Papanastasiou G. Effect of chemical structure on degree of conversion in light-cured dimethacrylatebased dental resins. Biomaterials. 2002;23:1819-29.

22- Silva EM, Almeida GS, Poskus LT, Guimarães JGA. Relationship between the degree of conversion, solubility and salivary sorption of a hybrid and a nanofilled resin composite: influence of the lightactivation mode. J Appl Oral Sci. 2008;16:161-6

23- Silva PCG, Porto-Neto ST, Lizarelli RFZ, Bagnato VS. Ortodontic brackets removal under shear and tensile bond strength resistance tests - a comparative test between light sources. Laser Phys. 2008; 5:220-6.

24- Stansbury JW, Trujillo-Lemon M, Lu H, Ding X, Lin Y, Ge J. Conversion-dependent shrinkage stress and strain in dental resins and composites. Dent Mater. 2005;21:56-67.

25-Sun GJ, Chae KH. Properties of 2,3-butanedione and 1-phenyl1,2-propanedione as a new photosensitizers for visible light cured dental resin composites. Polymer. 2000;41:6205-12.

26- Uhl A, Sigusch BW, Jandt KD. Second-generation LEDs for the polymerization of oral biomaterials. Dent Mater. 2004;20:80-7.

27- Wendl B, Droschl H, Kern W. A comparative study of polymerization lamps to determine the degree of cure of composites using infrared spectroscopy. Eur J Orthod. 2004;26:545-51.

28- Yap AU, Lee HK, Sabapathy R. Release of methacrylic acid from dental composites. Dent Mater. 2000;16:172-9. 